Social Capital, Lifelong Learning and the Management of Place

\title{
An international perspective
}

Edited by MICHAEL OSB MW. KATE SANKEY and BRUCE WISGIN 


\section{Social Capital, Lifelong \\ Learning and the \\ Management of Place}

An international perspective

Edited by

Michael Osborne, Kate Sankey

and Bruce Wilson

Routledge

LONDON AND NEW YORK 
First published 2007

by Routledge

2 Park Square, Milton Park, Abingdon, Oxon, OX14 4RN

Simultaneously published in the USA and Canada

by Routledge

270 Madison Ave, New York, NY 10016

Routledge is an imprint of the Taylor \& Francis Group, an informa business (C) 2007 selection and editorial matter, Michael Osborne, Kate Sankey and Bruce Wilson; individual contributions, the contributors

Typeset in Times New Roman by

Keystroke, 28 High Street, Tettenhall, Wolverhampton

Printed and bound in Great Britain by

TJ International Ltd, Padstow, Cornwall

All rights reserved. No part of this book may be reprinted or reproduced or utilised in any form or by any electronic,

mechanical, or other means, now known or hereafter invented,

including photocopying and recording, or in any information

from the publishers.

Every effort has been made to ensure that the advice and information

in this book is true and accurate at the time of going to press.

rowever, neither the publisher nor the authors can accept any legal

In the case of liability for any errors or omissions that may be made.

of the use

of technical equipment mentioned within this book, you are strongly

$5 \mathrm{Co}$

British Library Cataloguing in Publication Dato

con

A catalogue record for this book is available from the British Library

SUE

Library of Congress Cataloging in Publication Dato

$A$ catalog record has been requested for this book

6 Ide

ISBN 10: 0-41 5-42795-9 (hbk)

DUT

ISBN 10: 0-415-42796-7 (pbk)

ISBNI0: 0-203-94553-0 (ebk) 


\section{Contents}

List of figures

List of tables

List of contributors

vii

ix

$\mathrm{xi}$

1 Introduction

MICHAEL OSBORNE, KATE SANKEY AND BRUCE WILSON

2 Quantitative indicators of social capital: measurement in a complex social context

RALPH CATTS

3 What should count as 'evidence' for effective 'situated policy'?

IAN FALK

4 Governance and community strengthening: a case study from Victoria, Australia

MICHAEL HESS AND DAVID ADAMS

5 Community efficacy and social capital: modelling how communities deliver outcomes for members

SUE KILPATRICK AND JOAN ABBOTT-CHAPMAN

6 Identity, local community and the internet

DUNCAN TIMMS

7 The empirics of social capital and economic development: a critical perspective

FABIO SABATINI 
8 Co-operation, networks and learning regions: network analysis as a method for investigating structures of interaction WOLFGANG JÜTTE

9 Communities of practice and purpose: making knowledge work in the university industry interface TONY HALL, DEIRDRE HOGAN, EAMONN MCQUADE, EMMA O'BRIEN AND RHONA SHERRY

10 Beyond the social capital rhetoric - an investigation of the use of social networks in the co-ordination of intra-enterprise activities: a case study of small-scale rural non-farm enterprises in Zimbabwe JETHRO ZUWARIMWE

11 Lifelong learning: institutionalisation and regulating mechanisms KORNELIA EFTIMOVA ILIEVA

12 Place-centric and future-oriented learning in the local village context ERIK WALLIN

13 Cities as engines of growth PATRICIA INMAN AND LARRY SWANSON

14 Rationalising public place commodification and the ramifications of this choice in Alberta, Canada THERESIA WILLIAMS

5 'Cultural presence' and disadvantaged groups: do HEIs make a difference?

LESLEY DOYLE

16 Sustainable development: the role of lifelong learning CORINNE VAN BEILEN, MAX VAN DER KAMP AND JACQUES ZEELEN

17 Conclusion 


\title{
Governance and community strengthening
}

\author{
A case study from Victoria, Australia
}

\author{
Michael Hess and David Adams
}

\section{Introduction}

From the mid-1990s and building on experiences from the community development strategies of the 1960 s and 1970s', community-based approaches to policy making and implementation have been adopted in many market-oriented democracies as governments have tried new ways of addressing the complexity of their tasks. The link between governance models and the likelihood of place-focused policies succeeding in particular areas was noted as a characteristic of this trend by European commentators (Geddes and Benington 2001). More recently, Considine's review of approaches over the last decade in European countries (2004a, 2004b) identified both the wide range of differences between the approaches used and the unevenness of their success. Despite this variety, his review finds that governance factors, that is to say the ways in which the links between people and institutions are established, are constantly crucial components of success. This is especially the case in respect of how local institutions and partnerships build networks which facilitate local level co-operation. This chapter explores the ways in which research can assist with the formation of government policies which facilitate the kinds of partnerships and networks which enable community strengthening.

For government, the changes required for a successful community strengthening policy can be divided into structural, instrumental and work culture/skills changes. Structural changes include: roles for the community sector; a role for local government as the steward of community strength; moves away from the programme format; and the organisation of democratic decision making within the policy function. The emerging problem here is that, in general, it is hard to see how departments based around centralised decision making and expert knowledge, with an institutional interest in defending 'their' territory, can succeed as bona fide partners in community strengthening. In terms of the instruments required to give community strengthening the greatest chance of success, we need to be thinking about the barriers presented by annual budgeting, fragmented grants, the planning fetish and the obsession with short-term monitoring and reporting. We also need to consider the opportunities we have at hand in instruments like output budgeting and community consultation. Challenges in the area of work culture and skills are 
more subtle. Here the entrenched orientation of many agencies towards public choice reasoning has had the effect of devaluing local knowledge and undermining the idea that public administration is about service. On one hand, in whatever form it takes, the cult of the expert undermines the possibility of effective community strengthening because it devalues knowledge from outside the circle of bureaucrats and consultants. On the other, market-oriented instruments, while strong on cost signals, are weak on community service.

For communities there are also serious challenges if community strengthening is to be made to work. One is the issue of sustainability. For any community the effort-reward balance of engagement with policy processes must be demonstrably positive if it is to be sustainable. So connections into local institutions which bring additional resources into the community are important. Another is the nature of leadership and involvement in the community. If there are too few activists in a community the work of engaging with policy processes and implementation will fall too heavily on too few people. Distributed leadership and broad engagement is necessary to spread the burden. Finally there needs to be tangible, and probably economic, benefit to the community to convince people that the cost of
maintaining their involvement is worth their while.

At State level in Australia, all governments now have a department, unit or minister responsible for community development. Victoria was the first to embark on this process and has the most developed whole-of-government communitybased approach. Two broad areas of interest have emerged from this experience. One is the actual experience of implementing community strengthening as a central policy in the State of Victoria. This has been evident in prominent policy documents (Victoria 2001), as well as in the establishment of and research undertaken by the Department for Victorian Communities (DVC) (Hess 2003; DVC $2004 \mathrm{a}, 2004 \mathrm{~b}, 2005 \mathrm{a}, 2005 \mathrm{~b}, 2006)$. The other is the need for some serious thinking about the coherence of the ideas underpinning the practices. Without a systematic thinking through of its fundamental principles and implications, community strengthening runs the danger of becoming no more than a passing policy fashion. If such coherence can be achieved, however, it may be possible to build the practices we are now observing into something genuinely new and valuable in addressing the increasingly complex problems of contemporary government in
market-oriented democracies.

\section{The practice: community strengthening in Victoria}

In the Victorian government's policy approach of the last five years, the nexus between community strengthening and governance has increasingly emerged as a significant factor in the likelihood of policy success. Considerable experience and action research now make it possible to understand how governance contributes to making community strengthening effective and what this implies for the future shape of public administration. The key governance issues which have emerged
from this practice are:

- the un is net institu

- the un centra operat

DVC has : as creating stakeholdes delivery or munity str. number of the instrum and 'how? approach ir

In terms realisation the simple implication tion and in Mounting i after their 1 Australian community advantage. cohesion (n communitie also showec low social c high levels of imprison

In terms policy aime tion is hardl: today is diff has a long $h$ with initiativ while in the and the rura communityare about bc being put in $\$ 780$ millior 
- the understanding that what makes a community strong is connectivity and it is networks which create the connections linking individuals and social institutions,

- the understanding that the relationship between such local level activity and central government processes needs to be based in partnership and cooperation.

DVC has sought to capture this in its definition of community strengthening as creating sustained networks through local-level partnerships involving key stakeholders and community representatives to achieve agreed policy and service delivery outcomes (Blacher 2005). At one simple functional level, then, community strengthening describes an approach to policy aimed at increasing the number of people who participate. The ideas which have underpinned this and the instruments which made it possible provide answers to the questions of 'why?' and 'how?' community strengthening has emerged as a whole government approach in Victoria.

In terms of ideas, Victoria's community-based policy approach began with the realisation that communities, be they of location or interest, are important for the simple reason that they are where people live their lives. This has a series of implications for government, not the least of which is that communities, of location and interest, shape both the perception and reality of government services. Mounting international evidence that strong communities are better able to look after their members and to access and use services has now been borne out in Australian research. For example, Vinson's Victorian study demonstrates that community strengthening interventions can drive a wedge in the cycle of disadvantage. This study found that children born into communities with low social cohesion (networks) had high school drop-out rates. Those born into disadvantaged communities with high social cohesion had much lower drop-out rates. The study also showed a link between communities with high levels of early school leaving, low social cohesion and imprisonment. Similar disadvantaged communities with high levels of early school leaving but with high social cohesion had low levels of imprisonment (Vinson 2004).

In terms of instruments, community strengthening describes an approach to policy aimed at increasing the number of people who participate. While participation is hardly a new phenomenon, its application in the processes of administration today is different in fundamental respects. The Victorian government, for instance, has a long history of working with communities, starting back as far as the 1970s with initiatives such as Neighbourhood Houses, Disadvantaged Sites, and AA Plans, while in the 1980s, Community Health, Landcare, the Rural Women's Network and the rural Employment Networks were important policy initiatives involving community-based participation. The differences in the contemporary policy settings are about both quantitative and qualitative factors. Not only are huge resources being put into the approach (the current $A$ Fairer Victoria programme is costed at $\$ 780$ million), but it is a thorough, whole government policy setting which makes 
it fundamentally different from the silo-based, project or programme delivery under

which most public administration has operated for the last 100 years.
While a whole government level commitment is essential to coherence and mainstreaming, it is not the levential to providing policy munity strengthening as a strategy for the level at which the benefits of comlevel at which the connections for delivering outcomes is clearest. Nor is it the the potential of community between basic values, governance processes and The evidence to supporth strengthening as a policy approach are most evident communities which in the contention that local level co-operation builds stronger complex policy problems comes, the preconditions for effectively addressing particular the relationship between bunnaturally, from the locality level itself. In the likelihood of successful com building trust, the new governance models and commentary (Alford 2004; Conmunity strengthening is reflected in the academic in the published work of

\section{The evidence: measuring community
strengthening}

While measurement is hardly new to administrative science both the type of measure and the impact of measurement for community strengthening make it an especially crucial activity. The immediate context in which measurement of community strengthening has taken place has been the need to balance economic and social factors in public administration. Under new public management practices, policy makers and public managers became adept at measuring. This added vital hard data to the public administration knowledge base and made measurement instruments de rigueur for government at all levels. One practical problem has been the tendency for measurement to be based around outputs rather the project or contract completion focus on what is being done rather than of particular work units, measures may based knowledge has the potential to on what impact this has had. Communitythat we see the results of policies. Furde address this because it is in communities residential electorates, it is in commerthore, in democratic systems based on Community-based measurs in communities of location that votes get counted. of political sustainability because un clear potential for decision makers in terms (NPMs) it can tell us how particular comme the National Performance Measures to policy outcomes.

however, measuring or even of community-based impact measures are accepted, areas is not simple. The definitining what they are in respect of particular policy has already been mentioned. the need to differentiate those A further need for definitional clarity is called for by community capacity and the social capital factors which lay the foundation for hinder efforts to transform institutional arrangements which facilitate and/or

account action

Comr of put

DVC he and env sustaina ways of evident munities activitie: commur. Engager one is th measure action $\mathrm{o}$ the part attention objective administ impacts potential connecte networks underpin some of of conne a say, tol on the fo network

Intern pation ex mental $\mathrm{h}$ lower cris for a com et al. 199 and Wor engagem Victoria, showed $\mathrm{t}$ ] help whe such as ir 
account of both the capacity factors and the means by which it can be turned into action which is effective in terms of policy.

\section{Community strengthening and the future of public administration}

DVC has defined strong communities as those endowed with social, economic and environmental assets and organisational structures that work towards their sustainable use and equitable distribution (DVC 2004b). In developing practical ways of bringing community into policy processes in Victoria, it has become evident that there is a causal connection between the strength of particular communities and the nature and extent of their members' engagement in community activities. Because of this, DVC has moved to measure the concrete activities of community engagement rather than the more abstract idea of community strength. Engagement activities have two advantages in terms of measurement. The simple one is that because these are activities which can be observed they are more easily measured than an abstraction like community strength. The subtle one is that the action of measurement itself adds status to engagement in general as well as to the particular activities which are being meassured. It does this by focusing attention on the fact that the activities have significance beyond their immediate objectives and that this is of importance for the way in which contemporary public administration seeks to balance fiscal and social objectives. Beyond the actual impacts of measurement, engagement activities are significant in assessing the potential of community strength as part of policy processes because they create connectedness and build networks. These characteristics of connectedness and networks within communities are, as we will see in the next section, fundamental underpinnings of the governance of the community-government interface. So some of the DVC indicators of community strengthening describe the outcomes of connectedness such as community safety, feeling there are opportunities to have a say, tolerance of diversity and the ability to get help when needed. Others focus on the forms of participation that enhance social connectedness and lead to local network formation.

International and Australian research findings show that the benefits of participation extend to personal and collective well-being reffected in: better physical and mental health; higher educational achievement; better employment outcomes; lower crime rates; decreases in maltreatment of children; and an increased capacity for a community to respond to threats and interventions (Coleman 1988; Vinson et al. 1996; Porter 1998; Berkman and Glass 2000; Lin 2001; OECD 2001; Szreter and Woolcock 2004). Overall, this body of research claims that community engagement diminishes the impacts of social disadvantage. Specifically in Victoria, the 2003 Community Adversity and Resilience Report (Vinson 2004) showed that social cohesion, measured by participation in sport and ability to get help when needed, is associated with lower levels of negative social outcomes such as increased rates of imprisonment and early school leaving. The association 
between participation and physical well-being noted internationally (Young and Glasgow 1998; Berkman and Glass 2000) is also reflected in the DVC findings (DVC 2004b, 2005a). So participation also has an independent positive effect on health (Young and Glasgow 1998). Given the weight of research opinion, it is hardly surprising to find that governments are trying many practical ways to enhance citizen participation as a means of addressing the specific problems and

priorities of local areas (Coleman and Gotze 2001; Gilchrist 2004).
A recent DVC research report, Indicators of Community Strength at Local
Government Area Level in Victoria (DVC Government Area Level in Victoria (DVC 2005a), builds on the previous work of the Indicators of Community Strength in Victoria report (DVC 2004b). The latter took time series data relating to 11 indicators of community strength from the Victorian Population Health Survey and applied it to four Local Governmen Areas (LGAs). The 2005 report adds to this by examining the indicats munity strength across all $79 \mathrm{LGAs}$ in Victoria. It includes not included in the first report: parental participation indes four new indicators organised sport; participation on decision-cipation in schools; participation in liking the community in which you live. From the viewpoint of deve

capacity to measure this engagement better public administration practices, the munity engagement cannot be legitim a vital activity for two reasons. First, commaking and implementation unless it is as part of the mainstream of policy measurement enables decision it is measurable. This is the case because confident that its outcomes makers to see the impacts of policy and to feel this measurement makes the conslate into community support. Second, because explicit, it provides a bridge between between policy objectives and outcomes of communicating the objectives of government and community. The problem is thus brought into the lives of people policy and establishing that the policy works from their direct experience. In this sense, mas which enable them to see its efficacy connecting the process (community engageasurement becomes a central issue by in implementation in crucial policy areas). Thent) to the outcomes (improvements indicators which can demonstrate both). The actual connecting point is through outcomes (e.g. improvements in safety process (e.g. rates of participation) and the communities agenda in government the well-being). The DVC experience of realities of measurement as a practical issuen points at the same time to the hard the act of measurement can bring to the in policy, and to this particular subtlety Victorian experience shows that the government community interface. The adds value to the policy process. The act of measuring community engagement that the indicators can also build a subtle value in measurement in this case is (e.g. that community engagement is bridge between the theoretical abstractions really need to know what a particular communic) and the practical reality (that we is a better understanding of the policy agenunity wants/needs). The desired result public administration might need to chang community and the ways in which policies.

The DVC research agenda around community engagement seeks to reveal the 
nature of the gap between what residents feel their communities need and how they feel government is responding to these needs. It is increasingly bringing together three themes. Firstly, the focus on indicators of community engagement is providing real knowledge upon which to base continued learning both for public administrators and community players. These indicators have been used in the published and internal documents upon which this chapter is based (DVC 2004b, $2005 \mathrm{a}, 2005 \mathrm{~b}$ ). Secondly, the indicators themselves are throwing new light on central problems of policy which have been overlooked in the recent past. These particularly include the risk and protective factors associated with social wellbeing and economic prosperity. The use of these indicators is providing us with an increased ability to compare the links between community and individual/ family strength. Thirdly, evidence is emerging on how 'governance' factors intermediate both family and community level dynamics. While it is taken up in the following section, it is worth noting here that DVC research now uses local government area boundaries to organise data. This is because of the insight that the robustness and outlook of local institutions - and how they choose to organise - is a key determinant of community strength.

In the DVC experience, then, measurement of community engagement has been important in clarifying the nature of community as a part of policy. It has also played a significant role in helping develop understandings of the characteristics of particular communities. The fact that these characteristics vary greatly makes this local-level research important if policy impacts in particular locations are to be really effective. Measuring at a community level also has the potential to reveal actual outcomes in ways at which we've previously only been able to guess. This enables policy makers to have a degree of certainty about the impact of allocating resources and particularly about how to target those allocations to maximise their real impact in the lives of people.

While efforts to develop more effective measures and to use them as part of policy process can tell us a lot about what is happening and how it is happening, they do little to address the deeper questions of why new practices are gaining momentum. In the case of community strengthening, this is compounded by the fact that there is as yet no single catchy title under which the changes in public administration described above can be conveniently grouped. There is, however, an argument that they do represent a fundamental change in the way in which government does business. While many of the ideas behind the practice are old, the ways in which they are being brought together and their implications for the structures and skills demanded of public administration indicate that there is room for an argument that they represent fundamental change for two reasons. First, the underpinning concepts which are legitimising the changes are so different from those they are superseding and are establishing a new set of meanings in public sector activity and the way in which it fits into society. This is underpinning the ways in which the knowledge being used in public policy and management is altering (Hess and Adams 2002). In broad terms this may be seen as a shift in the approach to knowledge from positivism to constructivism. This 
change is significant for the way in which we go about the business of government in many of its aspects because under it the drivers of activity and the judgements about the efficacy of that activity shift from being located within the processes of government to being located in the relationships between government and communities of location and/or interest. The second element of paradigm shift in the contemporary public policy and management is that the new concepts are proving powerful in illuminating issues of public policy and management which have proven impervious to orthodox understandings and instruments. In particular, it may be seen as a response to deficits in NPM outcomes.

One implication is that rather than being a discourse resistant to external ideas, because they represent sectional interest, public administration increasingly becomes involved in an active search for new interpretive ideas and instruments because they reflect the experience of particular policy communities. So in epistemological terms traditional positivist approaches describe problems and identify the knowledge required to address these. They then either develop that knowledge within the processes of training bureaucratic experts or import it in the form of hired expertise. In an alternative constructivist approach, policy work actually interprets and constructs the meanings of the ideas and what constitutes usable knowledge about the ideas in any given policy area. Rather than searching for the 'right' definition of such ideas and applying objective knowledge to the rational pursuit of ranked goals, the constructivist approach posits that policy networks and the discourse within the networks constitute policy and policy commences of what constitutes the 'objective' of ideas. These include the basic constructs areas. A partial conceptualictive' or the 'rational' knowledge in particular policy tions of positivist public administation difference is that the fundamental quesWhat is the relevant expertise? a constructivist approach are What is the cost? On the other hand, those under involved? How can new know about 'how': how can the appropriate people be particular policy setting?

\section{Conclusion}

Community has come into public management in a relatively unsystematic way. Because it has lacked a single coherent body of theory to underpin it, there is a possibility that it will remain just a series of isolated instances of clever pracof the communitioms they encounter in their daily operations. The experience in these changes than ad in Victoria indicates that there is more potential approach to the knowledge base of the nolving and that adopting a constructivist standing its significance and to systemew practices provides both clues to underimplications are issues of how the skills aning its practice. Among the practical work need to change to generate and and organisation of public administration If government is to integrate community best use of this new knowledge.

servants

build tru needs to Australi:

In sun ment im complex non-line ways of beginnin

Refere

ABS (Aus and $F u$ $\mathrm{au} / \mathrm{web}$

Alford, J. govern Works,

Berkman, health' Univer:

Blacher, Comm

Coleman, Sociolo

Coleman, Deliber

Considine Govern.

Considine Melbou

Considine whose 1 Govern

DVC (De] Works:

DVC $(200$

DVC (20)

Victoria

DVC $(200$ Carolin

Geddes, M Európec

Gilchrist, P. Mille World?, 
servants will need the skills required to 'put oneself in another person's shoes and build trust' (Davis and Rhodes 2000: 96). Some work on linking the theory of what needs to be done with the practical issues of how to do it is already happening in Australia (Hess and Adams 2002; Reddel 2004), but more is required.

In summary, the move towards a community focus in public policy and management implies a straightforward logic of change. In order to address the non-linear complexities confronting policy makers in market-oriented democracies, we need non-linear structures, non-positivist knowledge and non-rational (not irrational!) ways of working. In the experience of community strengthening we are seeing the beginnings of what this might mean for the future of public administration.

\section{References}

ABS (Australian Bureau of Statistics) (2000) Measuring Social Capital: Current Collections and Future Directions, discussion paper, November, Canberra, at: http://www.abs.gov. au/websitedbs/D3110122.NSF/0/6CD8B1F3F270566ACA25699F0015A02A?Open.

Alford, J. (2004) 'Building trust in partnerships between community organisations and government', paper presented at the Conference on Changing the Way Government Works, new interests - new arrangements, Melbourne, 5 October.

Berkman, L.F. and Glass, T. (2000) 'Social integration, social networks, social support, and health', in L. F. Berkman and I. Kawachi (eds) Social Epidemiology, Oxford: Oxford University Press.

Blacher, Y. (2005) 'Changing the way government works', speech given to Engaging Communities 2005, United Nations Conference, Brisbane.

Coleman, J.S. (1988) 'Social capital in the creation of human capital', American Journal of Sociology, 94: S95-S121.

Coleman, S. and Gotze, J. (2001) Bowling Together: Online Public Engagement in Policy Deliberation, London: Hansard Society.

Considine, M. (2004a) Building Connections: Community Strengthening and Local Government in Victoria, Melbourne: Department for Victorian Communities.

Considine, M. (2004b) Community Strengthening and the Role of Local Government, Melbourne: Department for Victorian Communities.

Considine, M. (2004c) 'Stronger communities through improved local governance: an idea whose time has come?', paper presented at the Conference on Changing the Way Government Works, new interests - new arrangements, Melbourne, 5 October.

DVC (Department for Victorian Communities) (2004a) Changing the Way Government Works: New Interests, New Arrangements, Melbourne: DVC.

DVC (2004b) Indicators of Community Strengthening in Victoria, Melbourne: DVC.

DVC (2005a) Indicators of Community Strength at Local Government Area Level in Victoria, Melbourne: DVC.

DVC (2005b) Indicators of Community Strength in Melton: A Discussion Paper for the Caroline Springs Partnership, Melbourne: DVC.

Geddes, M. and Benington, J. (eds) (2001) Local Partnership and Social Exclusion in the European Union - New Forms of Social Governance?, London: Routledge.

Gilchrist, A. (2004) 'Developing the well-connected community', in H. McCarthy, P. Miller and P. Skidmore (eds) Network Logic: Who Governs in an Interconnected World?, London: DEMOS. 

Hess, M. (2003) 'Governance and knowledge in the post-market state', Canberra Bulletin
of Public Administration, 109: 33-36.

Hess, M. and Adams, D. (2002) 'Knowing and skilling in contemporary public administration', Australian Journal of Public Administration, 61(4): 68-79. Klein, H. (2004) 'Neighbourhood renewal: revitalising disadvantaged communities in
Victoria', Public Administration Today, September/October: 20-29.

Lin, N. (2001) Social Capital: A Theory of Social Structure and

Cambridge University Press.

OECD (Organisation for Economic Co-operation and Development) (2001) of Nations: The Role of Human and Social Capital, Pevelopment) (2001) The Well-being org/publications/e-book/9601011E.PDF. Porter, M.E. (1998) 'Clusters and the new.

Review, 76 (6): 77-90.

Reddel, T. (2004) 'Exploring the institutional dimensions of local governance and community strengthening: linking empirical and theoretical debates', paper presented at the Conference on Changing the Way Government Works, new interests - new
arrangements, Melbourne, 5 October arrangements, Melbourne, 5 October

and the political economy (2004) 'Health by association? Social capital, social theory, 33: $1-18$.

Conference on Changing the Wayure community strength?', paper presented at the ments, Melbourne, 5 October.

Victoria (2001) Growing Victoria Together. Innovative State. Caing Communites, Melbourne: Department of Premier and Cabinet. Vinson, T. (2004) Community Adversity abinet.

Disadvantage in Victoria and Nersity and Resilience: The Distribution of Social Cohesion, Melbourne: Jesuit Social South Wales and the Mediating Role of Social Vinson, T., Baldry, E Jesuit Social Services.

abuse', British Journal of Social Work, 26(4): 23 . Neighbourhoods, networks and child Wiseman, J. (2004) 'Community strerk, 26(4): 523-543.

paper presented at the Conference Interests - New Arrangements, Young, F. and Glasgow, N. (1998) 'Volbourne, 5 October.

Aging, 20(3): 339-362.

For over h

(Pearse a)

a commu

mental ar

(Eckersle

causal lin

being outs

the Unite

social sup

but, at the

indicators

capital, w

Statistics

finding $\mathrm{r}$

building, : all note the are lookin ventions, communit participati

We cor munity mi 'elements may be id and locai and polics achieve $\mathrm{d} \epsilon$ Chapman 